DOI: $10.20472 / T E .2020 .8 .1 .005$

\title{
CULTIVATING STUDENTS' COMMUNICATION SKILLS FOR THE GLOBAL WORKPLACE: A CROSS-CULTURAL ONLINE EXCHANGE PROJECT WITH NON-NATIVE SPEAKERS
}

\author{
KATE SATO, BIRTE HORNE
}

\begin{abstract}
:
Teaching English as a Foreign Language (EFL) at universities with a distinct focus on science and engineering, we have found that one of the major challenges is a perceived lack of motivation in our students. Though acknowledging the theoretical importance of English as the lingua franca of science and business, students often do not appreciate the importance of its practical application when they enrol in technical degree courses.

In order to stimulate and engage our students, we introduced a communicative business project to our respective courses from 13th April 2018 - 22nd June 2018. Our aim was to provide a very practical and first-hand experience of how English may be an essential part of professional interaction. In groups, students were asked to produce two short videos. The first was an introduction of their team and the second gave business advice pertinent to a person visiting their country from the other country. To accomplish these assignments, students had to communicate regularly with their partner-group via a chat app on their mobile phones. Thus, cross-cultural communication was not only encouraged but became a crucial tool to complete given tasks successfully. Despite a number of hindrances, the students were able to complete the task and also said they benefitted from doing the project. Further projects were planned however, more research is needed to illuminate what factors helped this project succeed.
\end{abstract}

\section{Keywords:}

tertiary EFL, asynchronous PBL, inter-cultural communication, business English

JEL Classification: 129

\section{Authors:}

KATE SATO, Hokkaido University of Science, Sapporo, Japan, Email: sato-ka@hus.ac.jp BIRTE HORNE, Hamm-Lippstadt University of Applied Sciences, Germany, Email: Birte.Horn@hshl.de

\section{Citation:}

KATE SATO, BIRTE HORNE (2020). Cultivating Students' Communication Skills for the Global Workplace: A Cross-Cultural Online Exchange Project with Non-Native Speakers. International Journal of Teaching and Education, Vol. VIII(1), pp. 64-83., 10.20472/TE.2020.8.1.005 


\section{Introduction}

This paper illustrates a cross-cultural project in an EFL context that was conducted between two groups of students at technical universities in Germany and Japan. Due to the geographical distance, the project was carried out using online tools and asynchronous video exchanges. The authors, i.e. the teachers from Japan and Germany, hoped to motivate their students in their English studies by giving them a very practical task and thus equipping them for their future in a globalized work environment.

This paper starts by giving some background information on the universities as well as potential factors that were expected to influence the project and the tool used for the project. The second part will review pertinent literature on skills that today's students are expected to need in their careers, the concepts of project-based learning and virtual teams as well as viewing potential cultural differences. In the third part, the project and its execution are presented in detail, followed by outcomes, a discussion and the conclusion.

\subsection{Background of the universities}

The Japanese university involved in this project is Hokkaido University of Science which is a private university. It has fourteen departments and five faculties which range from Health and Science to Human Sciences. All courses are four-year courses except for the Faculty of Pharmaceutical Sciences which offers a six-year course. At the time of writing it has approximately 5,000 students and is one of the largest universities in Hokkaido. The English levels of the students ranges from CEFR levels pre-A1 to C2. Motivation to study English is generally low, and many students struggle to communicate in English after having studied through the traditional grammar-translation methods taught during the six years of combined compulsory classes in junior high and senior high schools. Furthermore, there are only a handful of foreign students studying at the university; at the time of the study there were two from Saudi Arabia, two from China one from Taiwan, and one from Malaysia.

The MEXT (Ministry of Education, Culture, Sports, Science and Technology) guidelines indicate when students graduate from High School they should have a level of English equivalent to a mid-high A2 CEFR (Common European Framework of Reference) level. At universities like Hokkaido University of Science many students have to pass national exams in order to pursue their chosen career. Therefore, English is not considered a priority. However, after graduating from university being able to communicate in English is becoming increasingly pertinent. In 2010 MEXT addressed the need for various skills needed postgraduation including in the planning for 'Global Human Resources' (Yonezawa, 2014) which states:

In the stage of a bachelor program, the environment, where students can constantly communicate in English with universities of multiple Asian countries, is maintained through the establishment of an IT network, etc. so that students can gain practical English speaking ability as a global communication skill

The Hamm-Lippstadt University of Applied Sciences (HLUAS) in Germany is a relatively young university, established in 2009, with a focus on STEM (science, technology, engineering and mathematics) degree programs. With c. 6000 students on both campuses, 
the university is medium-sized with strong connections to small-and-midsized enterprises in the region.

On two campuses, there are four departments with fourteen bachelor and ten master programs. Most of those focus on engineering and computer sciences. Notable exceptions are two more business-oriented bachelor programs in Business Administration and Intercultural Business Psychology. All programs are in German ${ }^{1}$, with some classes, such as Business English or Technical English being taught in English. Though English is generally acknowledged as an important tool for international business, motivation to improve their English is relatively low among students. Proficiency ranges from A2-C1 with most students having had between seven and nine years of English language instruction before they come to university. In general, HLUAS students are able to communicate fairly well in English, though incorrect usage of grammar, a relatively basic active vocabulary and pronunciation issues are frequent. At high school level, independent use of English, speaking freely and engaging in discussion are encouraged. Later, at university, a certain standard of English language proficiency (B1-B2) is expected from students. This, however, does not necessarily reflect reality. Especially at science-focused universities of applied sciences, foreign languages are often considered 'soft skills' that are given only minimal space - if any - in the curriculum. Students are frequently not interested in learning or using languages or might even feel uncomfortable having to speak in class as they consider their proficiency too poor. With cross-cultural exchange projects such as this, students recognize the value of being able to communicate with partners from different countries even if their English may be far from perfect. They realize that English can be used as an instrument for very practical purposes and experience academic and personal successes using the language. Furthermore, students also gain competencies in communication, cultural awareness and will be able to contribute these skills to their careers later in life.

International students have been part of the HLUAS' make-up for several years. Though not large in number, there have been students from various African countries enrolled in engineering programs since the earliest years of the university. For the past three years, a double degree program with a Chinese university has increased the number of Chinese students on one of the campuses, as well. In 2018 the first degree-program in English (electronic engineering) has led to a further diversification of the student body with c. 150 international students at the Lippstadt campus at the time of writing.

For German students, contact with students from other countries is often not entirely new. Many high schools have partner schools in countries such as France, Great Britain or the United States and facilitate exchanges that are very popular. Consequently, communication and cooperation with students from other countries is more often considered an interesting challenge than an intimidating task.

\subsection{Potential Influencing Factors}

There were a number of external factors that had the potential to impact the project in both positive and negative ways. These include motivation and anxiety in Japanese students

\footnotetext{
${ }^{1}$ In 2018, the bachelor program 'Electronic Engineering' was re-structured and is now taught entirely in English.
} 
(which is referred to below in the avoidance dimension), the different academic calendars of the two universities, and working across different time zones. These are discussed below.

In Japan students have six years of compulsory English education ${ }^{2}$ in secondary school, and then they have to have a further eighteen months of English education upon entering HUS. Anecdotal evidence from Sato, as teacher, asking the students in one of her classes 'Who does not like English?' and seeing a raise of hands, a conservative estimate indicates over $80 \%$ of students did not like English. Motivation to continue studying English by the Japanese students is generally low.

Additionally, students in the Media department in the Japanese university are known to be reserved. Speaking out in class is not an integral part of the Japanese culture although there are government initiatives to integrate more active learning and collaborative activities in classes in Japanese tertiary education. The Japanese education, founded on Confucian philosophies adheres to respect for those older and more experienced than oneself (Sato \& Sakabe, 2018). Therefore, teaching English where students are expected to be active, produce language and use it (rather than study the grammar and complexities of the linguistic elements of the language) is fraught with obstacles that have to be overcome.

The academic year in Germany starts in September and goes through to July (with a twomonth break in February and March). In Japan the academic year starts in April and classes finish in February the following year with an eight-week summer break in August and September. The slight difference in semester timings creates a limited opening in which a project can be carried out. With Horn and Sato first meeting in April 2018, this was the start of the academic year in Japan, Sato's second year working full-time in Hokkaido University of Science and therefore the second time to teach the class this project was to be implemented in. After seeing students' shyness in the previous year, it was clear a project such as this would not only widen the scope of the syllabus, but potentially motivate the students to apply their knowledge of English in a real-life situation. Nevertheless, preparations for the project would have to done by the teachers working at a distance, and with a time-lag.

\subsection{The communication tool: LINE}

As mentioned above, the tool used for communication was the application LINE. LINE was launched in 2012 in Japan (LINE Corporation) and has expanded to other countries such as Taiwan, South Korea, and Thailand. It is predominantly a social networking service (SNS) tool where the user can send text, photo, files (e.g. pdf), audio and video messages to individuals or groups.

The application is primarily for smartphones and once that app has been installed, a desktop version can be installed and linked to the mobile app. One of the main advantages of using the LINE app is that no personal information needs be exchanged in order to add someone to your list of contacts. The LINE app produces a personal QR code which can be sent to another person as a photo (e.g. a PNG file attachment if the QR code was taken as a screenshot.). If the other person has the LINE app on their phone, they can then use the app's QR code reader to read the code and add the new contact. When a contact is no

\footnotetext{
${ }^{2}$ Compulsory English education is now from Elementary school in Japan.
} 
longer needed in the contact list the contact can be deleted from the list. These processes are simple and quick. All messages are encrypted. However, there is one disadvantage to using LINE in that as it is a robust app it also takes up approximately $700 \mathrm{MB}$. Nevertheless, according to the Google Play app store LINE has over 11 million users to date and ranks no. 1. In 52 countries (Google, 2019).

There are a number of peripheral services and functions to LINE however only some are of interest in this project. Those that are not relevant will not be mentioned. LINE has stickers and emoji that can be used to illustrate the feelings, etc of those communicating. Anecdotal evidence shows that students in the Japanese university sometimes communicate using only stickers. Some stickers are available in only one language, and some are available in two, or more. Needless to say, this makes them indispensable as well as being extremely popular. They can be bought from the LINE sticker store, and some are available for free (examples are shown in Figure 1 below).

There are three other features of the LINE chat that bare mentioning for this project. The first is, after a message is sent it can be deleted. There are options for deleting the message. For example, it can be deleted only for the sender, or for both sender and receiver. The second feature is the sender can see when the message sent has been read. In a group this feature indicates the number of people that have read the message which makes LINE suitable for this project. The third is a person can start to write a message, change to a different app, or chat in the app, return hours later and their message is there, ready to be finished and sent. For students who are writing messages, and may have frequent interruptions when writing, this is very useful and facilitates the communication.

\section{Figure 1: Examples of LINE stamps showing emotions}

\section{Showing surprise 2. Showing disagreement 3.Showing uncertainty}
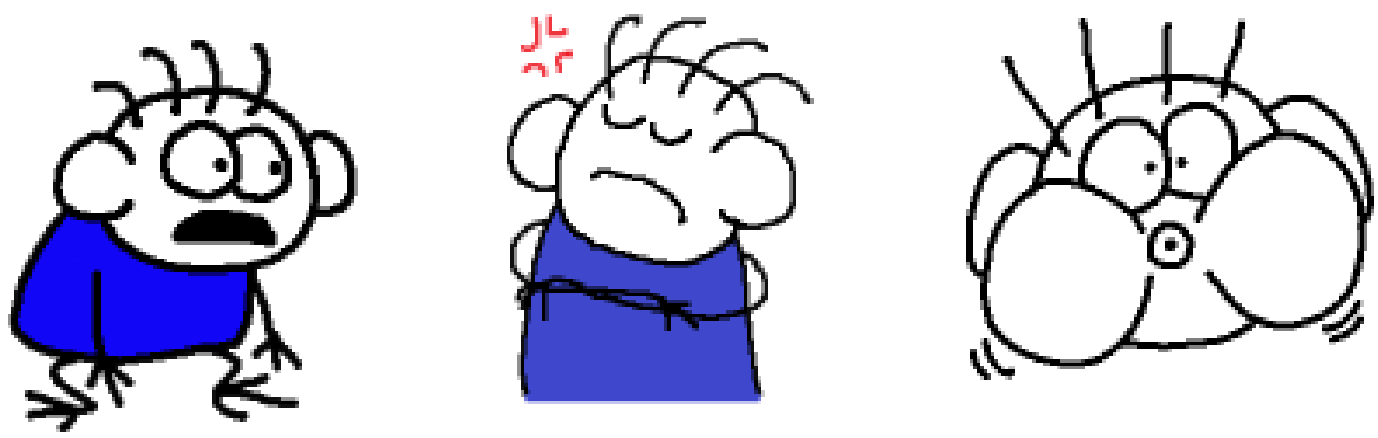

Taken from the Spike Collection created by Rob Olson (used with permission)

\section{Literature review}

As mentioned above, this section includes literature that covers the skills perceived as being necessary for our students' futures, project-based learning virtual global teams, cultural dimensions and finally agency. 


\subsection{Skills needed for graduates today}

In a rapidly changing world, driven by technological progress and globalization, students in tertiary education face several challenges: social, economic and environmental (Howells, 2018. P.2). To help young adult learners to succeed in navigating these challenges, organizations such as the OECD, the World Economic Forum or the Programme for International Student Assessment (PISA) have developed sets of life-long learning skills and competencies to prepare learners for their role in a global workplace (ibid). These skills, which are often referred to as $21^{\text {st }}$ century skills, demand that the 'educational systems equip young people with new skills and competencies, which allow them to benefit from the emerging new forms of socialization and to contribute actively to economic development under a system where the main asset is knowledge' (Ananiadou, K. and Claro, M., 2009, p. $5)$.

Among these skills and competencies, communication plays a major role. The OECD stresses the importance of this competency for young people to have the ability to communicate exchange, criticise, and present information and ideas, including the use of ICT [Information and Communications Technology] applications to participate and make positive contributions to the digital culture' (ibid, p.10). Communication is then further subdivided into 'effective communication' and 'collaboration and virtual interaction' (ibid.)

This last area has been in the focus of the project discussed here, between media students at the Hokkaido University of Science, Japan and the Hamm-Lippstadt University of Applied Sciences in Germany. In this project, the students had to communicate in English for the purpose of a) communicating effectively with students from the other country, and b) collaborating on the creation of an advisory video on business etiquette in their own culture to help visitors from the other country.

Aside from the life-long learning skills, project-based learning was one of the teachers' methods to develop the students' English communication skills and intercultural competence. Consequently, project-based learning as one of the crucial factors in the project, will be discussed below.

\subsection{Project-based learning}

The term project-based learning (PBL) has been increasingly used in Japanese education. PBL is attractive as takes the focus off the teacher towards a more student-centred class. Traditionally students learning English in the Japanese education system have studied in teacher-centred classrooms with an emphasis on understanding the language through grammar-translation methods. In Japan there has been a gradual shift toward active learning in tertiary education. For this reason, PBL is an attractive model to implement in tertiary English classes in Japan. However, what PBL is needs to be defined.

Thomas (2000, p.2) points out that the defining characteristics of PBL include complex tasks 'based on challenging questions or problems, that involve students in design, problemsolving, decision making, or investigative activities; give the students the opportunity to work relatively autonomously over extended periods of time; and culminate in realistic products or presentations' as well as including authentic material. However, it can be argued that the degree to which projects may be challenging is going to vary depending on the culture and 
mindset of a student. Furthermore, this broad stroke explanation can be rather misleading and further examination is needed.

Thomas (ibid, p.4) continues to point out there are five components to PBL, the first of which being centrality of the project in the curriculum (or syllabus). As planning for the project started at the beginning of the Japanese academic year the syllabus had already been published and therefore a complete change to $100 \%$ centrality for the project in the syllabus was not possible. However, having complete autonomy over the class and syllabus, a certain degree of flexibility was possible. Thus, the project was added to the class providing an authentic situation in which to apply the language that was being covered in the textbook. As Thomas' says 'projects are the curriculum' therefore, if the textbook were a tool to facilitate the project work then arguably a weakened form of PBL was taking place. Therefore, in this study strong PBL was not possible, but a weak PBL was.

In the German class, the project was also added after the start of the academic year. In the 'Business English' course for the German students, 'intercultural communication' is already part of the syllabus. Usually, this topic is taught on a rather theoretical level. Including a project with partners in Japan was considered to be an excellent opportunity to give this particular area a more authentic relevance. The project was included into the syllabus with the results making up $30 \%$ of the students' final grade.

In his introduction of common features for PBL, Simpson (2011) has pointed out several advantages or benefits for the students: the activities are student-centred, their agency increases; students need to use a variety of skills such as social skills and management skills and the students create something meaningful together that is shared with peers and teachers.

In the EFL classroom, PBL is able to challenge all four language skills, listening, speaking, reading and writing in the course of the project. The students develop metacognitive skills as any project requires a number of individual and cooperative task and, last but not least, while working together, students can increase their confidence and independence as English learners (Thuan, 2018).

One of the most important advantages to employing PBL in the English classroom is that students can take agency in their studies. Agency in the EFL classroom is increasingly being discussed. Duff (2015) (cited in Lee \& Wright, 2014) explains how agency offers the opportunity for a platform where 'learners are not simply passive or complicit partners in language learning and use, but can also make informed choices, exert influence, resist... or comply...'. Agency gives students more responsibility and a more personalised choice in their language learning. Lee \& Wright $(2014$, p.4) state, "[a]gency as a construct...can afford and constrain language-learning opportunities depending on the sociocultural context and the intentions of the learner'. Therefore, for tertiary level students being able to choose the content of their video, having complete autonomy over communication and the language used with their partners overseas, they could choose to engage with new language and incorporate it into their learning and presentations to varying degrees.

Another very significant facet of this project was international communication. This is becoming an increasingly relevant skill in a globalized world where global virtual teams are becoming more common. 


\subsection{Global Virtual Teams}

Sheppard, Dominick, \& Aronson argue that 'global virtual teams are likely to be a fixture in the life of professional engineers' (2003, p.13). However, global virtual teams are doubtless not only going to be limited to professional engineers. Therefore, university students from various courses, and cultural backgrounds should be given the opportunity to participate in a VGT in order to 'help prepare them for their future' (ibid, p. 13).

With regard to the global virtual teams involved in this project, one has to mention the different premises of the students, i.e. their home countries and the respective international contexts.

Germany is a land-locked country in the heart of Western Europe with nine neighbouring countries. Consequently, many Germans are used to immediate contact with people speaking other languages and coming from different cultural backgrounds. In the 1950s and 60 s, an influx of so-called 'guest workers' from countries like Turkey, Italy, Spain and Greece led to an increase of citizens with a migration background; the third and fourth generations now living in Germany. Political developments in the EU, the easy mobility between countries, along with a common European currency being shared by nineteen countries all have increased the degree to which Germans are used to connecting with people from other countries. German students have opportunities to interact with people from different backgrounds, cultures and language groups from a very early age. At HLUAS there are currently about 150-200 international students on the campus where the project was carried out. However, even with a certain (albeit at times rather theoretical) background in globalization, certain factors unique to VGTs can be of great benefit to German university students and will be pointed out further down.

Japan is an archipelago separated from the rest of Asia. Therefore, young Japanese may not experience interacting with people from other backgrounds, cultures and language groups to the same degree as their European counterparts. Also, prevalent amongst the students in Japan at the time was that mind-set that international communication in English might be useful in the future, but the degree of necessity was certainly not perceived as acute. Therefore, having the experience to participate in a virtual project was an invaluable experience for students in Japan.

Participating in an international virtual project provides opportunities for students to learn a number of skills including leadership, collaboration and awareness of cultural preferences (Sheppard, Dominick, \& Aronson, 2003). However, in order to facilitate the learning of these skills, careful instruction by the teacher(s) is necessary. As O'Hara-Devereaux \& Johanson (1994) (cited in Sheppard, Dominick, \& Aronson, 2003) have pointed out: a virtual context can increase bad behaviour and attitudes.

One reason is difference in time zones. In a virtual global team (VGT), asynchronous and cross-culture communication are factors that influence the team and the team's project. In the project described here, there is a 7-8-hour difference between the two countries (depending on the season). For the most part, if students in Japan contact their German counterparts in the morning, it is night time in Germany and there will probably be a delayed response. If the Japanese students contact their German partners in the evening, when it is morning in Germany, the partner may be busy travelling to university or is in a morning 
class. Thus, the answer may be sent later in the day and will only reach the Japanese partner some time during the night.

This asynchronous communication has potential problems that can be reduced by laying 'ground rules that stress ... consistency and frequency' (Sheppard, Dominick, \& Aronson, 2003). Making expectations clear to students and rotating leadership roles were two suggestions made by Sheppard, Dominick, \& Aronson (2003). Hafner and Ellis address the issue of 'freeloaders' (2004, p. 6) through evaluation methods. They recommend including both group and individual evaluation in the collaborative assignment. This can be achieved if roles are clearly defined, or expectations are clearly stated.

Hafner \& Ellis (2004) note that, "[t]he nature of the communication pathways is directly related to the assignment structure', and Sheppard, Dominick, \& Aronson, 2003 say using a reliable tool for communication can help increase trust between the groups of students. As stated below, for this project LINE was used.

Sheppard, Dominick, \& Aronson (2003) recommend keeping track of students' behaviour. In this project, keeping track was done by collecting data over a three-week period to see how often the groups were exchanging posts. The number of posts was used for grading purposes in Japan as suggested by Sheppard, Dominick, \& Aronson (2003).

When working in VGTs, the issue of culture is something that necessarily has great impact on the team's project. Consequently, cultural dimensions and their potential influence on the exchange project will be illustrated below.

\subsection{Cultural Dimensions}

The six dimensions which emerged from Geert Hofstede's cross-cultural study have been used in business, education and society around the world. While these dimensions may have changed a little since the 1970s, and have seen some criticism (McSweeney, 2002; d'Iribarne, 1996, 2009), they may help to understand behaviour and business practices of those from other cultures. Therefore, those dimensions deemed relevant to this project are explained briefly below from a comparative perspective between Germany and Japan, based on G. Hofstede, and G.J. Hofstede's, 6-D model of national culture (2017). The first dimension deemed relevant to this project is that of collectivist-individualist cultures. According to the dimensions, the culture in Germany is more individualist whereas in Japan it is more collectivist. This may surface in how the groups work, how they approach and execute the project. Collectivist cultures may need more time to for decision making as consensus is sought by all members. However, depending on the leadership of the group, this may also not be the case.

A further dimension with potential impact is the power distance index. The power-distance dimension illustrates how power is distributed (unequally or equally). Every culture recognises leadership, but the extent to which the leader has power varies from culture to culture. The power-distance score for both countries is below 60 with Germany's being just over half that of Japan's. This means in this project it is expected that there will be more hierarchy in the classroom in Japan, than in Germany. One question for further study would also be if a difference in power distance can also be observed in inter-group communication. 
Another dimension that may evidence in this project is that of uncertainty avoidance as this dimension illustrates how the culture views uncertainty or the unknown and whether it tends to analyse or trust the unknown. Uncertainty avoidance for Germany is such that it means there may a small degree of hesitance in participating in this project for the first time. The uncertainly avoidance for Japan, however, is very high which means there could be considerable anxiety in participating in a project like this especially for the first time.

The degree to how these attributes may influence the project or even be evidenced in the data may be somewhat limited due to the small numbers of participants in this study. Furthermore, Hofstede (2001) found that over time the scores for countries may increase or decrease. Nevertheless, the teachers' awareness of cultural dimensions and their potential influence working on a cross-cultural project such as this, can only be of benefit to the participants. They will start their careers in an increasingly global market where overseas acquisitions and mergers are becoming more frequent (Zahid \& Shah, 2011).

A recent example of a successful Japanese-European merger is that of Renault and Nissan. Zahid \& Shah (ibid) state the reason for the success is because of 'strong and effective leadership' (p. 45). This supports Hofstede who argues that 'strategic management today almost invariably involves cross-cultural elements. As a result, cross-cultural understanding is now strategically important' $(2015, \mathrm{p} .2)$

As discussed above, communication is a skill essential for the future workforce, and knowing every group has its own culture it is therefore logical to expose and help students in tertiary education today to increase their ability to communicate across cultures. Furthermore, an acquisition or merger may result '[i]n a multinational workforce, [where] the relationship between company practices and home culture values is typically different for employees from different cultures. Adhering to company practices does not imply sharing the same culture' (Hofstede, 2015, p. 14). Consequently, this increases the need for cross-cultural understanding for the future workforce.

Having highlighted some of the theoretical concepts involved, a more detailed description of the project will follow below.

\section{The project}

\subsection{Concept}

The concept for the project was formulated at the 2018 IATEFL conference in Brighton where both teachers were presenting. On finding they were both teaching English in science universities, they were both surprised to find they were facing a similar lack of motivation in their classes. Consequently, they started exchanging ideas how to increase motivation by including a cross-cultural experience for their students. Furthermore, Horn had a year of experience working in Japan which facilitated an understanding of the Japanese context. Sato, being of British birth and upbringing and having taught English in Europe could also appreciate various elements of the German context. Therefore, there was a mutual understanding of each other's context which facilitated collaboration in the management of the project. Taking their cultural backgrounds, organizational or institutional educational goals as well as class aims into consideration, common threads were kneaded out and the project started to take form. The basic concept was for the students to collaborate, communicating in English in order to produce a measurable outcome. This concept required 
the students to use the English as a tool, rather than studying the language itself, which aligns with potential future situations after graduating from tertiary education. Also, in this project the students were not required to talk face-to-face, thus reducing potential for anxiety. However, as being able to confidently speak in English is an obvious advantage, it was decided that spoken elements would also be included in the tasks.

\subsection{The Students}

In Japan the project was conducted in a third-year elective class for students studying Media Design. There were nineteen students in the class. The academic year in Japan starts in April, and elective students have approximately three weeks to enrol and decide if they want to take an elective course. Nevertheless, the project was outlined to the students in the first week of classes during the orientation and in the second week more information was given. In the weeks following, information was repeated as guidance throughout the project was given. The project was done in conjunction with textbook work, but was carried out as a stand-alone activity.

The thirty-two German students who participated in the project were in their first year of studying 'Applied Computer Sciences and Social Media,' a bachelor program, which combines computer sciences with media design. The project was introduced as part of the mandatory 'Business English' course to give students an opportunity to improve intercultural competence and knowledge of business etiquette in other countries. Though the curriculum for the course was taught as usual, the project was incorporated as part of the class, counting for $30 \%$ of the final grade. Summer term at HLUAS usually starts towards the end of March, beginning of April. Thus, students were introduced to the project a few weeks into the term.

Students were divided into teams to provide easier communication. However, due to a higher number of participants from Germany, there was a certain imbalance to the groups. Altogether there were six groups, consisting generally of four to six German students and three to four Japanese students. Table 1 below provides a short comparison of the students and their respective degree programs.

Throughout the project data was collected in various ways. Before the project began, there was a pre-project survey with questions on the students' perception of the other country. This was drafted by the teacher in Germany and revised by the teacher in Japan. There were eight questions, and both questionnaires asked the same questions to the students. Some of the outcomes are illustrated below. This survey was executed on paper, scanned and archived in a joint Dropbox folder of the teachers. As this type of survey was felt to be rather cumbersome, later surveys were collected by way of the online platform SurveyMonkey. Using an online survey, students could use their smartphones or laptops to complete the survey and for the teacher it was easier to collect the results afterwards. Another method to receive feedback from the students was the feedback module of a Moodle learning platform. Throughout the project and after it was completed, data was also collected through informal chats in class. Students willingly shared their opinions about the project. 
Table 1: Background information of the participants.

GERMANY

32

NUMBER OF
PARTICIPANTS

DEGREE PROGRAM

AVERAGE AGE

AVERAGE YEARS

OF LEARNING

ENGLISH

COURSE TITLE

COURSE TYPE

$20-25$

$9-11$

$\begin{array}{cc}32 & 20 \\ \text { Media and Communication } & \text { Media Design } \\ \text { Technology (Undergraduate) } & \text { (Undergraduate) }\end{array}$

20

8

Business English

English Conversation

Mandatory, $1^{\text {st }}$ Year Course

Elective, $2^{\text {nd }}$ Year Course

\subsection{Execution}

For the teachers to be able to use any data gathered in the project all of the students in both countries were asked to give their informed consent. The students willingly agreed to informed consent allowing the dissemination of the data from this study.

For the project, the students were divided into six groups in each class in both countries. Then each group created a joint LINE group, so that Group 1 in Japan was connected to Group 1 in Germany on LINE.

The first part of the project was to create a c. 3-minute-video in which each group was asked to introduce themselves. This was meant to give their partners in the other country a better idea who they were working with.

To help students prepare for the second task, a video giving advice to a foreign business partner about typical business etiquette in one's own country, five guiding questions were given to the students. These questions were, e.g. 'is there overtime, is it paid,' or 'what clothes are suitable for the work environment'. Students had to find answers to these questions from their partner groups. Later, their findings were discussed in class.

The second part was to give advice to a business visitor from the other country about what to expect in the home country's business behaviour.

For the second video, students received feedback according to a matrix which was developed for this task by the teacher in Japan. While watching the videos created by the teams from the other country, students would remark, e.g. on the usefulness of the content, clarity of expression and voice as well as further notes on content and performance. After watching, the students' feedback was communicated to the respective groups in the other 
country. This type of assessment was an important instrument for the students as they received an evaluation of their final tasks from a peer group. At the same time, this task also challenged the students to give feedback to the others in an appropriate language.

At the end of the project, students were asked to answer a post-project questionnaire regarding their experiences and their opinions on the project. The outcomes of this survey are discussed below.

\subsection{Skills needed for the project}

In order to successfully communicate with their partners in the other country and to achieve the requested tasks, students had to be able to use various forms of technology. For individual communication, the chat app LINE was used. This app is very popular in Japan and the German students were able to adapt easily. Using an app familiar to the Japanese students helped the project seem less intimidating and thus reduced one potential hindrance to communication although one or two Japanese students showed a mild interested in learning to use WhatsApp, an app used widely in Germany but less familiar to most Japanese students. Some German students explicitly mentioned that it was interesting getting to know a different chat app with unknown types of emoji and stickers. As media students, both teachers also expected the project participants to create advanced quality videos. This, however, was not achieved in all cases.

One of the most important skills for this project was the English proficiency of the students. As will be discussed below, the range of English proficiency was very diverse. While some of the Japanese students had an effective proficiency of A1-A2, most German students were at B1-B2 levels. Even though working in groups helped to balance weaker and stronger students in this regard, communication was at times complicated by misunderstandings based on lack of English skills.

Life skills needed for the project were effective communication as well as collaboration and virtual interaction (Ananiadou, K. and Claro, M., 2009). Students conversed via LINE to get to know each other and achieve a number of given tasks.

Other skills students needed to bring into the project were a certain open-mindedness towards the other culture and patience. Though one might argue that 'patience' is less a skill than a virtue, it can be learned and developed to a certain point. As Roberts has pointed out, '[e]very external pressure, social and technological is pushing the students ... toward immediacy, rapidity, and spontaneity' (2013, p.40). Accordingly, this skill was often somewhat problematic, especially for the German students who are used to very direct and low-context communication.

\subsection{Evaluation \& Grading}

In Germany, as the project was carried out in a mandatory class, the project counted for $30 \%$ of the final grade. For the German teacher it was important that the students were able to use English as an instrument to 'conduct business,' i.e. communicate with colleagues from another country to collect information for completing a specific task. Aside from the videos, participation in regular feedback sessions and overall activity in the project were also evaluated. 
In Japan, the project was part of an elective class, and the project was $50 \%$ of the overall course grade. The project was clearly explained to the students during the first week's course orientation, so students were fully aware of the course components when deciding to enroll. The $50 \%$ of the grade included the self-introduction, the business advice video, and also, a reflection activity that was conducted at the end of the project as well as the LINE activity. The aim of the class was to help students practice conversational skills in English, so rehearsing for the project could be done in the classroom using the textbook, while the project provided an authentic platform through which to expand the students' experience of communicating using English.

\section{Outcomes}

In answer to the questionnaire 'Impression of [other country name]'answers from German students showed a fairly stereotypical image of the other country. Replies tended to focus on food (sushi, rice, ramen), sports such as football or sumo, manga and anime as well as a strong gaming and electronics industry. Questions probing for deeper knowledge such as 'do you know anything about Japanese history' or 'what are working hours in Japan' were commonly met with the answer 'I don't know'. Answers from the Japanese students were similar focusing on food (potatoes, sausages and beer), and cars. Akin to the knowledge of the German students, Japanese students had very limited, or no knowledge about German history, or working hours.

In the introductory video quite a few German students chose to film their individual introductions at their homes, showing gardens or pets, or even while being on vacation. This provided a very personal insight into their daily lives and life in Germany in general. The Japanese students, on the other hand, chose to film only their faces, either in a room in the university or in at their home. Also, the videos made by the Japanese students were generally shorter in comparision to the vidoes from the German students. For the most part they were under one minute.

The second video proved to be quite a challenge for both German and Japanese students. Often, they would simply stand in front of the camera and explain something or had an offscreen narration while giving some information on CVs or contracts. Only one German group created a fully animated video, which was something the teachers had hoped to see more, given that all students had a background in media studies. Two Japanese groups gave very good advice. Both of these groups used role-plays to illustrate their information. The first group showed examples of apologies and the second group explained seating arrangements in order of hierarchy. In the examples of apologies, the students demonstrated various degrees of bowing to getting on one's knees to apologise. With seating arrangements, the Japanese students demonstrated how the more important members of a group should be seated furthest from the door in a meeting. These videos were a great example of how cultural dimensions, in this case Hofstede's Power Distance Index, are reflected in and influence business behaviour.

It could also be argued that evidence of respect for one in authority (the teacher) emerged in the Japanese classroom. As mentioned above, collecting the data for the number of LINE posts was done in the Japanese classroom, this was announced in class the week the data collection started. The students willingly obliged to count the number of posts that week with no hesitation. 
The German students were excited to receive feedback from their Japanese colleagues and the teacher could observe a general increase in motivation as well as a rise in students' confidence working in English. However, this was not without challenges. Coming from a very low-context culture, they tended to be very direct in their communications and initially expected the same in return. When they did not receive a response within a day or two from their Japanese partners, they often became impatient. After discussing this issue with the teacher, students were later able to understand the concept of shyness in Japanese culture and became a little more patient in their communication.

Table 2: The number of LINE posts by group.

\begin{tabular}{|c|c|c|c|c|}
\hline \multirow[b]{2}{*}{ Country/group } & \multicolumn{3}{|c|}{ Dates in June 2018} & \multirow{2}{*}{$\begin{array}{l}\text { Total line } \\
\text { messages } \\
\text { per group }\end{array}$} \\
\hline & $3-9$ & $10-16$ & $17-24$ & \\
\hline Japan 1 & 105 & 10 & 40 & 155 \\
\hline Japan 2 & 16 & 20 & 6 & 42 \\
\hline Japan 3 & 20 & 0 & 0 & 20 \\
\hline Japan 4 & 16 & 10 & 12 & 38 \\
\hline Japan 5 & 4 & 0 & 1 & 5 \\
\hline Japan 6 & 21 & 0 & 36 & 57 \\
\hline Germany 1 & 72 & 7 & 1 & 80 \\
\hline Germany 2 & 27 & 47 & 2 & 76 \\
\hline Germany 3 & 26 & 0 & 0 & 26 \\
\hline Germany 4 & 8 & 17 & 3 & 28 \\
\hline Germany 5 & 3 & 0 & 1 & 4 \\
\hline Germany 6 & 26 & 0 & 16 & 42 \\
\hline Total LINE messages & 344 & 111 & 118 & 573 \\
\hline
\end{tabular}

During the last three weeks of the project, students were asked to count every post in their group chats. This was meant to raise awareness of their own communication behaviour.

The data in Table 2, above, shows that Group 1 in Japan was the most active group on line throughout the three weeks of data collection. The most active week was during the $1^{\text {st }}$ week of data collection. Week 2 shows a slight decrease followed by more posts again in week 3. Overall one can see clearly that in some of the groups, communication was stronger and worked better than in others. Consequently, the group dynamic in a project such as this is a highly influencing factor for the outcome.

At the end of the project, a further questionnaire was given to all students asking, e.g. about changed perceptions of the other country after the project, increased knowledge about the 
other country, things that surprised them in the interaction with their partners from the other country and a general evaluation of the project.

The results show that fourteen out of the nineteen students in the class in Japan liked the project component of the class they best. From the project the students mentioned three distinct things they learned: culture, business manners, and communication. Communication ranked the highest with nine of the nineteen students mentioning this is what they learned. However, two of the students said they did not like the LINE communication as they were 'shy'. In the Japanese culture being 'shy' or reserved is socially acceptable.

The German students were initially very enthusiastic going into the project. However, as communication with their overseas colleagues proved difficult at times, students became frustrated and their motivation decreased. Though they enjoyed the dialogue with their Japanese colleagues in general, German students openly shared their concern whenever they felt the project was not proceeding as well as hoped and requested assistance from the teacher. In the feedback, some students mentioned that they felt the Japanese were very shy, and that communication did not quite go as they had expected. Several students expressed that they perceived the scarcity of communication as a lack of interest on the side of their Japanese partners. One student also commented on having expected a better level of English from their Japanese partners. Interestingly, one student remarked on the difference in using a chat app for communication, saying 'how to chat and using emojis is quite different so that sometimes it came to misunderstandings'. This is something that needs to be addressed when implementing a project where communication via an app plays an important role.

Table 3: Student Feedback on the Business Video Exchange Project 2018 (Semester 1 Media Students in Japan)

\begin{tabular}{|c|c|c|c|}
\hline Question & \multicolumn{3}{|c|}{ Answers } \\
\hline $\begin{array}{l}\text { What did you like best about the } \\
\text { class this semester }\end{array}$ & $\begin{array}{l}\text { Exchanging } \\
\text { videos }\end{array}$ & $\begin{array}{l}\text { The Line } \\
\text { Chat }\end{array}$ & Other \\
\hline (no. of responses) & 9 & 5 & 5 \\
\hline $\begin{array}{l}\text { What did you learn from the video } \\
\text { exchange activity }\end{array}$ & culture & $\begin{array}{l}\text { business } \\
\text { manners }\end{array}$ & communication \\
\hline (no. of responses) & 7 & 3 & 9 \\
\hline $\begin{array}{l}\text { Ideas to improve the exchange } \\
\text { project include: }\end{array}$ & \multicolumn{3}{|c|}{$\begin{array}{l}\text { practice more, add subtitles to the video, } \\
\text { speak more clearly, real-time calling, and } \\
\text { watching an example video. }\end{array}$} \\
\hline $\begin{array}{l}\text { Ideas to improve the exchange } \\
\text { project include: }\end{array}$ & \multicolumn{3}{|c|}{$\begin{array}{l}\text { have more communication, have quicker } \\
\text { responses, have a conversation theme, make } \\
\text { short sentences, and one student suggested } \\
\text { switching to FB. }\end{array}$} \\
\hline
\end{tabular}


On the question of the value of using video exchange to learn about the other country and teach about their own, German students were generally very positive, giving comments like: 'I find this idea good because you could exchange more and imagine better', or 'it is a cool and interesting idea which was a lot of fun. It is different if you have direct contact to Japanese people and learn directly from them', and 'very good idea to see the emotion and character from the Japanese. This is difficult to see in a text.' While the majority of responses were positive, some German students felt that a synchronous exchange such as using Skype would be better to learn about their partners on a more personal level.

Concerning improvements for future projects, German students suggested that tasks could be more clearly defined, they wished for more exchange on a personal level and that an assignment where all students in one group, i.e. both German and Japanese participants, worked on a common task would help to increase the contact and learn about their partners' lives.

\section{Discussion}

While the expectation of both teachers was that media students should be able to create high quality videos, as mentioned earlier, this was not always the case. There are a number of potential reasons for this. One is that time constraints might have been a problem. Another is, as Sheppard, Dominick, \& Aronson (2003) stated, clear expectations and rotating roles help reduce problems that surface in asynchronous communication. Role rotation was not implemented for this project. Furthermore, the expectation of the teachers may not have been communicated clearly enough for the students. As the reason is unclear this needs further investigation.

As stated above, one component of PBL is having a challenging question or problem. In this project the students were working, communicating, and negotiating towards a quantifiable outcome in a second language. The students' studies focused on media studies; thus, English was a tool they had to use. In this project, the Japanese students' English level was possibly CEFR (Common European Framework of Reference) A1. On the other hand, most German students were at a B1 or B2 level. Therefore, the language barrier added complexity to what may be viewed as a relatively simple project and created a significant challenge. To counteract this language barrier, the aim of the project did not focus on language level, so the pressure to produce grammatically accurate language was not high for the students. Therefore, the complexity of the task was not in the problem, but more the way the goal could be achieved.

\subsection{Challenges and Solutions}

Different challenges emerged. The most problematic was extreme variations in frequency of communication. Aside from encouraging students to keep chatting, we established 'chat protocols'.

Since the number of students complaining about infrequent communication increased throughout the semester, for the last three weeks of the project $\left(3^{\text {rd }}-24^{\text {th }}\right.$ June 2018) the Japanese and German students kept a record of the number of LINE posts written by them and their counterparts in the other country. Noting the number of posts, which has been mentioned above, was not announced in advance and started in class on the $9^{\text {th }}$ of June, and then weekly for the following two weeks. Thus, students had no prior knowledge they 
would count the posts. Table 2, above, shows the number of LINE posts by group. It was instigated by the teacher in an effort to promote awareness of each group's activity in the hope that less active groups would show an increase.

As explained above, for three weeks communication frequency was recorded. This helped strengthen communication a little. Nevertheless, often students in both countries commented on replies being late. This could be a perception as working asynchronously with time delays is inevitably going to increase the possibility for posts to be forgotten or left for a more convenient time, and then later forgotten. In order to increase punctual replies a reminder system would need to be established, but how to do this needs careful consideration. It is also possible that the virtual context proliferated bad behaviour (O'Hara-Devereaux \& Johanson, 1994 as cited in Sheppard, Dominick, \& Aronson, 2003). A possible starting point might be to bring awareness of the possibility of delays in replies and having the students think of ways to prevent, or minimise it.

Though all groups were set to communicate via LINE and had created a video to introduce themselves, there was no synchronous meeting of the students. Furthermore, the groups were rather large, with eight to ten students each, which resulted in a lack of personal connection and responsibility. One solution would be to have smaller groups, or ensure students make their own groups, grouping with friends that already have trust bulit up between group members and good relationships. Alternatively, a possible solution might be having teams of only two students working together and adding synchronous video meeting if the schedule, and time difference, allows. Another solution would be to have clearly defined roles within the groups as Sheppard, Dominick, \& Aronson (2003) suggest.

Another issue that emerged later was different goals and expectations from both teachers and students. The German students were supposed to work on a specified task using English as a tool; the Japanese students were to use English as a form of communication. For future projects, clearer goals with a focus on outcomes will be established in the planning phase.

As noted above the Japanese students' level of English was lower than that of their German counterparts. One student said they were shy at communicating, even using LINE, but overall the Japanese students struggled to express themselves and showed surprise at the German students being so open and expressive. Through the experience the Japanese students noted that becoming more expressive (including using more facial and bodily gestures in the videos) could help improve communication.

\section{Conclusion}

Even though both teachers had slightly different goals in executing the project, the overriding goal was to connect Japanese and German students from a similar academic background to increase their ability to communicate in English as well as their intercultural competence. Sato and Horn had hoped to amplify students' motivation to speak and write English and strengthen their understanding of the importance of English as a global language for business and science. In this aim they were successful as the mostly positive feedback from the students showed. For the teachers it was also a great learning experience with several issues to be optimized in further projects. 
Future recommendations include paying particular attention to the timing of the video exchanges in order to allow for sufficient turn-around time. Maintaining good communication between teachers is essential for the smooth running of the project, and exchanging two videos over nine weeks was a comfortable number. More reflective practice for the students to evaluate their videos might result in better videos.

Despite some minor issues, the majority of the students enjoyed the project very much. They appreciated the opportunity to communicate and work with colleagues from another country. Overall, we noticed increased motivation from the students in the classroom, especially, but not only, when working on the project. Although it was a challenge for some students, they needed to and succeeded in using English for the tasks given.

Overall the project was a positive experience for the students in both countries with both the LINE correspondence and the video exchanges adding a different dimension to the class. With the regular coursework that had to be completed, the students still enjoyed the project and interaction with students from overseas. It was a good opportunity for the Japanese and German students involved to reflect on their own language skills, learn something new about a different culture, whilst teaching something about their own culture.

\section{References}

Ananiadou, K. and Claro, M., 2009. 21st century skills and competences for new millennium learners in OECD countries, No. 41, OECD Publishing.

d'Iribarne, P., 2009. National cultures and organisations in search of a theory: an interpretative approach. International Journal of Cross Cultural Management, 9(3), pp.309-321. https://doi.org/10.1177/1470595809346601

d'Iribarne, P., 1996. The usefulness of an ethnographic approach to the international comparison of organizations. International Studies of Management \& Organization, 26(4), pp.30-47. https://doi.org/10.1080/00208825.1996.11656693

Google 2019. Play app, viewed on 6th December 2019, $<$ https://play.google.com/store/apps/details?id=ip.naver.line.android\&hl=en>

Hafner, W. and Ellis, T.J., 2004, January. Project-based, asynchronous collaborative learning. In 37th Annual Hawaii International Conference on System Sciences, 2004. Proceedings of the (pp. 9-pp). IEEE. https://doi.org/10.1109/HICSS.2004.1265065

Hofstede, G. and Hofstede, G.J., 2017. The 6-D model of national culture, viewed on 6th December 2019, <https://geerthofstede.com/culture-geert-hofstede-gert-jan-hofstede/6d-model-of-nationalculture/s

Hofstede, G., 2001. Culture's consequences: Comparing values, behaviors, institutions and organizations across nations. Sage publications.

Hofstede, G.J., 2015. Culture's causes: The next challenge. Cross Cultural Management, 22(4), pp.545-569. https://doi.org/10.1108/CCM-03-2015-0040

Howells, K., 2018. The future of education and skills: education 2030: the future we want.

Lee, J.S. and Wright, W.E., 2014. The rediscovery of heritage and community language education in the United States. Review of Research in Education, 38(1), pp.137-165. https://doi.org/10.3102/0091732X13507546 
LINE Corporation, viewed on 6th December 2019, <https://linecorp.com/en/company/info>

McSweeney, B., 2002. Hofstede's model of national cultural differences and their consequences: A triumph of faith-a failure of analysis. Human relations, 55(1), pp.89-118. https://doi.org/10.1177/0018726702551004

MEXT 2010. The Concept of Global Human Resource Development Focusing on the East Asian Region, viewed on 15th December 2019, < https://www.mext.go.jp/en/policy/education/highered/title02/detail02/sdetail02/1373900.htm>

Olson, R. 2019. Spike Line Collection Stamps.

Roberts, J.L., 2013. The power of patience. Harvard Magazine, pp.40-43, viewed on 16th December 2019,

< http://www.harvardmag.com/pdf/2013/11-pdfs/1113-40.pdf $>$

Sato, K. and Sakabe, T., 2018, October. To what extent is the Course Experience Questionnaire applicable to Japanese Education? In Proceedings of International Academic Conferences (No. 7008494). International Institute of Social and Economic Sciences. https://doi.org/10.20472/IAC.2018.042.043

Sheppard, K., Dominick, P. and Aronson, Z., 2003. Preparing engineering students for the new business paradigm of international teamwork and global orientation.

Simpson, J., 2011. Integrating project-based learning in an English language tourism classroom in a Thai university.

Thomas, J.W., 2000. A review of research on project-based learning, viewed on 3rd December 2019, $<\quad$ https://www.asec.purdue.edu/lct/HBCU/documents/AReviewofResearchofProjectBasedLearning.pdf>

Thuan, P.D., 2018. PROJECT-BASED LEARNING: FROM THEORY TO EFL CLASSROOM PRACTICE. In Proceedings of the 6th International OpenTESOL Conference (pp. 327-339).

World Economic Forum, 2015. New vision for education: Unlocking the potential of technology. British Columbia Teachers' Federation.

Yonezawa, A., 2014. Japan's challenge of fostering "global human resources": Policy debates and practices. Japan Labor Review, 11(2), pp.37-52.

Zahid, N. and Shah, A.M., 2011. Mergers and acquisitions in international business. European Scientific Journal, 22, p.43. 